\title{
Efeito do Genótipo Halotano e de Diferentes Sistemas de Produção na Qualidade da Carne Suína ${ }^{1}$
}

\section{Ana Maria Bridi², Jane Maria Rübensam ${ }^{3}$, Sergio Nicolaiewsky4, Rui Fernando Felix Lopes ${ }^{5}$, José Fernando Piva Lobato ${ }^{6}$}

\begin{abstract}
RESUMO - Verificou-se o efeito dos genótipos halotano homozigoto dominante e heterozigoto e dos sistemas de criação confinado sobre piso de cimento, confinado sobre cama de maravalha e ao ar livre sobre a qualidade da carne suína. Foram utilizados 96 suínos machos castrados selecionados através do exame de DNA genômico, utilizando-se a técnica de reação em cadeia de polimerase (PCR) para amplificar a região do receptor rianodina. A região amplificada foi clivada pela técnica polimorfismo do comprimento dos fragmentos de restrição (RFLP). Mediu-se o pH nos músculos Longissimus dorsi e Semimembranosus aos quarenta e cinco minutos e vinte e quatro horas após o abate. A capacidade de retenção de água foi avaliada em amostras do músculo Longissimus dorsi através das técnicas de perda de líquido por gotejamento, de cocção e de descongelamento. Escores para a cor e o grau de marmorização da carne foram atribuídos com auxílio de padrões fotográficos. A maciez da carne foi medida pela força de cisalhamento em equipamento Warner-Bratzler Shear. Suínos com gene halotano heterozigotos apresentaram valores inferiores de $\mathrm{pH}$, menor capacidade de retenção de água e uma freqüência de carcaças com carne PSE três vezes maior. O sistema de criação não afetou os valores de pH inicial e final ou a capacidade de retenção de água da carne suína. A maior incidência de carne PSE foi observada nas carcaças dos suínos criados em sistema confinado sobre piso de concreto. Não houve efeito significativo da interação genótipo halotano e sistema de criação para as características avaliadas.
\end{abstract}

Palavras-chave: criação ao ar livre, criação sobre cama de maravalha, gene halotano, PSE

\section{Effect of the Halothane Genes and Rearing Systems on Meat Quality of Pork}

ABSTRACT - The effect of halothane genotypes (heterozygous and dominant homozygous) and intensive rearing systems (indoor, wood shavings bedding and outdoor) on pork quality were determinated. Ninety six castrated male pigs were used for the trial. Identification of the halothane genotype was determined in blood samples using the DNA-test, based on the polymerase chain reaction (PCR) amplification of the critical region of the ryanodine receptor and subsequent restricion of the amplifield fragment by the restriction fragment lengh polymorfism (RFLP) technique. The pH at 45 minutes and 24 hours after slaughter was measured on the Longissimus dorsi and Semimembranosus muscles. At the laboratory, the Longissimus dorsi muscle was used for the evaluation of the color, marbling, drip loss, defrosting loss and cooking loss and shear force. The muscle of heterozygous pigs for the halothane gene had lower $\mathrm{pH}$ and higher drip loss and the incidence of the PSE condition in this genotype was three times higher. The rearing system did not affect the initial and ultimate $\mathrm{pH}$ or water holding capacity. Indoor reared pigs had greater frequency of PSE carcass. The interaction between halothane genotypes and rearing systems had no significant effect on any trait studied.

Key Words: halothane gene, outdoor rearing system, porcine meat quality, PSE, wood shavings bedding

\section{Introdução}

Atualmente, a suinocultura mundial encontra-se em pleno processo de mudanças. Por um lado, o aumento da demanda por proteína animal, principalmente nos países em desenvolvimento, exige aumentos na produção e na produtividade. Porém, a sociedade anseia que os sistemas de produção causem o menor impacto no meio ambiental e que os animais sejam criados em condições mais humanitárias (Gibon et al., 1999). Como a qualidade da carne é uma medida das características desejadas e valorizadas pelo consumidor, além dos aspectos sensoriais e tecnólogicos, considerações éticas dos sistemas de criação e o impacto que estes provocam no meio ambiente estão sendo incorporados para conceituar a

${ }_{1}^{1}$ Trabalho originado na tese de doutorado do primeiro autor e parcialmente financiado pelo CNPSA/EMBRAPA.

${ }^{2}$ Aluna de Doutorado do Programa de Pós-Graduação em Produção Animal da UFRGS. Av. Rio de Janeiro, 814, apt. 102. Londrina, PR. E.mail: ambridi@hotmail

3 Professora Adjunta IV,Faculdade deVeterinária/UFRGS. Av. Bento Gonçalves 9090. Caixa Postal 15094. CEP 91540-000. Porto Alegre. RS.Jane@orion.ufrgs.br.

${ }^{4}$ Professor Adjunto IV, Departamento de Zootecnia/UFRGS, Caixa Postal 776, 90.001-970. Porto Alegre. RS. nicola@vortex.ufrgs.br.

${ }^{5}$ Professor do Departamento de Ciências Morfológicas-ICBS/UFRGS. Pesquisador Associado do Centro de Biotecnologia/UFRGS junto ao Laboratório de Biotecnologia Animal Aplicada.rfflopes@dna.cbiot.ufrgs.br.

${ }^{6}$ Professor Adjunto IV, Departamento de Zootecnia/UFRGS, Caixa Postal 776, 90.001-970. Porto Alegre. RS. lobato @orion.ufrgs.br. 
qualidade da carne (Warriss \& Brown, 2000). A produção intensiva de suínos confinados sobre cama ou ao ar livre podem ser alternativas dentro de uma nova perspectiva de um sistema de criação mais humanitária e ecológica.

Barton-Gade \& Blaabjerg (1989) e Enfält et al. (1997) verificaram que suínos criados ao ar livre possuíam maior taxa de glicose no músculo no momento do abate, levando à maior produção de lactato nos processos bioquímicos pós-morte. Esses animais apresentaram valores inferiores de $\mathrm{pH}$ da carne 45 minutos e 24 horas após o abate que aqueles criados confinados, resultando em uma maior incidência de carcaças com carne PSE. Entretanto, Warris et al. (1983), Jones et al. (1993) e Van der Wal et al. (1993) não encontraram diferenças nos valores de $\mathrm{pH}$ inicial e final e na freqüência de carnes PSE entre os dois sistemas de produção.

O gene halotano aumenta o conteúdo de carne na carcaça suína mas exerce um efeito deletério sobre a qualidade da mesma. Suínos portadores de uma ou duas cópias do gene halotano apresentam valores inferiores de $\mathrm{pH}$ na carne logo na primeira hora após o abate, o que provoca um aumento na incidência de carne PSE, sigla internacional para denominar carne de coloração pálida, de textura mole e exsudativa (Sather et al., 1991; Leach et al., 1996; Ellis, 1998; Tam et al., 1998; Monin et al., 1999; Channon et al., 2000; Fisher et al., 2000; Hamilton et al., 2000; Culau et al., 2002).

O objetivo deste trabalho foi investigar o efeito dos genótipos halotano (homozigoto dominante e heterozigoto) e de diferentes sistemas de produção (confinado sobre cimento, confinado sobre cama de maravalha e ao ar livre) sobre a qualidade da carne suína.

\section{Material e Métodos}

O experimento foi conduzido na Estação Experimental da Faculdade de Agronomia, da Universidade Federal do Rio Grande do Sul, localizada no município de Eldorado do Sul - RS, nos meses de abril a julho de 2000. Os animais foram abatidos no matadouro frigorífico Doux Frangosul, localizado na cidade de Caxias do Sul - RS, distante 150 km da Estação Experimental Agronômica.

Foram utilizados 96 suínos machos castrados da genética AGROCERES ${ }^{\circledR}$ provenientes do cruzamento de fêmeas CAMBROUGH 22 e machos
AGPIC 419. Os animais com mais de 60 dias de idade foram selecionados através do exame de DNA genômico.

O DNA genômico foi extraído a partir de amostras de sangue (Miller et al.,1988) e submetido à reação em cadeia de polimerase (PCR). Utilizou-se um par de oligonucleotídeos específicos (MHF: 5'-GTTCCCTGTGTGTGTGCAATGGTG-3' e MH-R: 5'TCTCTAGAGCCAGGGAGCAAGTTCTCAGTAAT-3') para amplificação da seqüência de DNA do gene receptor rianodina suíno (Fujii et al., 1991). Os produtos de amplificação foram clivados com a enzima HhaI, através da técnica polimorfismo do comprimento dos fragmentos de restrição (RFLP), e submetidos à eletroforese em géis de agarose (Sambrook et al., 1989). A digestão do fragmento com a enzima de restrição HhaI produziu dois fragmentos de 49 e 32 pares de bases para suínos homozigotos normais, três fragmentos de 49, 32 e 81 pares de bases para heterozigotos e um fragmento de 81 pares de bases para os suínos homozigotos recessivos mutantes.

Os suínos foram alojados em baias ou piquetes em grupos de quatro animais. As baias mediam 4,6 m de comprimento e 1,80 m de largura, correspondendo a uma área de $2 \mathrm{~m} 2$ por animal. As baisa utilizadas pelos suínos do tratamento com cama receberam uma camada de aproximadamente $30 \mathrm{~cm}$ de maravalha, que era trocada parcialmente sempre que alguma área se encontrava úmida. O sistema de criação intensivo ao ar livre estava localizado em uma área ao lado do galpão de terminação. Constituiu-se de 16 piquetes de $500 \mathrm{~m} 2$ cada, sendo a densidade de 125 $\mathrm{m}^{2}$ por animal. Os piquetes foram usados em forma de rodízio, para evitar a compactação do solo.

Todos os animais do experimento receberam a mesma ração comercial à vontade. A ração inicial continha 3,38 Mcal de energia metabolizável por quilo de ração e $18 \%$ de proteína bruta, enquanto as rações de crescimento e terminação possuíam, respectivamente, 3,30 e 3,25 Mcal de energia metabolizável por quilo de ração e 17 e $16 \%$ de proteína bruta.

Os suínos foram abatidos com peso médio de $91,0 \mathrm{~kg}$. Para facilitar a coleta dos dados no frigorífico, os animais foram abatidos em dois grupos, com diferença de uma semana entre os abates.

No dia anterior ao abate, a ração foi retirada ao meio dia, permanecendo os animais em dieta hídrica. Os animais foram carregados às vinte e duas horas e transportados até o abatedouro, percorrendo uma distância 150 km. No abatedouro, os animais do 
experimento ficaram reunidos em uma mesma baia com acesso irrestrito a água. No dia do abate, os animais foram pesados às cinco horas da manhã e abatidos entre sete e oito horas da manhã. Os suínos foram contidos em limitadores do tipo $\mathrm{V}$ e insensibilizados via corrente elétrica, com o uso de dois eletrodos. A sangria dos animais ocorreu na horizontal.

As medidas de $\mathrm{pH}$ foram realizadas nos músculos Semimembranosus e Longissimus dorsi, na altura da última costela, aos 45 minutos após o abate $(\mathrm{pH}$ inicial) e após um período de 24 horas de resfriamento a $2^{\circ} \mathrm{C}$ ( $\mathrm{pH}$ final). A leitura do $\mathrm{pH}$ foi realizada dentro da câmara de resfriamento utilizando-se um aparelho portátil com eletrodo de inserção (NWKbinär pH K21). A temperatura muscular foi verificada nos músculos Semimembranosus e Longissimus dorsi, na altura da última costela, com o uso de um termômetro de inserção digital, aos 45 minutos após o abate .

As carcaças foram classificadas como PSE quando apresentaram valores de $\mathrm{pH}$ inicial inferiores a 5,8 e como DFD, sigla internacional para designar carne de coloração escura, de textura firme e seca, quando os valores de $\mathrm{pH}$ final foram iguais ou superiores a 6,0 (Warris \& Brown, 1987).

Foram coletadas, de cada animal, após 24 horas de resfriamento em c6amara frigorífica, entre 0 e $2{ }^{\circ} \mathrm{C}$, três amostras de $2,5 \mathrm{~cm}$ de espessura do músculo Longissimus dorsi a partir da articulação da última vértebra torácica com a primeira vértebra lombar em direção à porção cranial do animal. No sentido crânio-caudal dos músculos dorsais, a primeira chuleta foi utilizada para avaliar a cor, marmoreio e medir a perda de água por gotejamento. Essas medidas foram realizadas no dia da coleta das amostras. As outras duas amostras foram congeladas em freezer doméstico a $-20^{\circ} \mathrm{C}$ para serem usadas posteriormente. A segunda chuleta foi usada para avaliar a perda de água no descongelamento e na cocção. Na terceira chuleta estimou-se a perda de água no descongelamento e na cocção e a força necessária para cisalhar a carne.

A capacidade de retenção de água foi avaliada pela perda de líquido no descongelamento e na cocção e perda de líquido por gotejamento. Para a avaliação da perda de líquido por descongelamento, pesou-se as amostras congeladas e após 24 horas à temperatura de $7^{\circ} \mathrm{C}$, dentro de saco plástico, para evitar o ressecamento das mesmas. Antes da pesagem foi retirado o excesso de umidade aderida à carne com o auxílio de papel toalha. Para a avaliação da perda de líquido pela cocção, retirou-se a porção óssea e o tecido adiposo das amostras descongeladas. Após serem pesadas e identificadas com ficha metálica, as amostras foram assadas em forno préaquecido à temperatura de $170^{\circ} \mathrm{C}$ até atingirem a temperatura interna de $70^{\circ} \mathrm{C}$. Após a cocção, as chuletas foram resfriadas a $7^{\circ} \mathrm{C}$ por 24 horas, sendo então novamente pesadas (Ellis et al., 1996).

Para avaliar a perda de água por gotejamento retirou-se da chuleta a porção óssea, o tecido adiposo e partes dos músculos espinhais e multífidos, mantendo-se a fáscia junto ao músculo. A amostra foi pesada e em seguida suspensa por um gancho de arame galvanizado, dentro de um saco de polietileno que, por sua vez foi colocado dentro de outro, de tal modo que restassem paredes duplas de plástico. Os sacos foram fechados sob pressão atmosférica e amarrados com um fio de sutura de algodão. As amostras permaneceram penduradas por 48 horas a $4^{\circ} \mathrm{C}$ em geladeira doméstica. Após, as amostras foraam retiradas da embalagem plástica e novamente pesadas (Boccard et al., 1981, adaptada por Ourique, 1989).

A cor e da taxa de marmorização foram determinadas após as amostras ficarem expostas ao ar por um período de aproximadamente 20 minutos, para permitir a oxigenação do músculo. Com o auxílio de padrões fotográficos (National Pork Producers Council, 1991) atribuíram-se valores para a cor ( 1 = rosa muito pálido; 2 = rosa pálido; 3 = rosada cinzento; 4 = vermelho escuro e; 5 = vermelho muito escuro) e para a taxa de marmorização ( 1 = traços; 2 = pequena; 3 = média; 4 = moderada; $\mathrm{e}$ 5 = abundante).

A maciez da carne foi avaliada através da medida da força de cisalhamento em equipamento WarnerBratzler Shear, conforme metodologia desenvolvida por Whipple et al. (1990).

O delineamento experimental utilizado foi completamente casualizados em esquema fatorial $2 \times 3$, dois genótipos, (homozigotos dominantes e heterozigotos para o gene halotano) e três sistemas de produção (confinado sobre cimento, confinado sobre cama de maravalha e ao ar livre), com dezesseis repetições por tratamento. Cada animal foi considerado uma unidade experimental.

O modelo matemático utilizado para a análise dos dados foi:

$$
\mathrm{Y}_{\mathrm{ijk}}=\mu+\mathrm{G}_{\mathrm{i}}+\mathrm{S}_{\mathrm{j}}+(\mathrm{GS})_{\mathrm{ij}}+\mathrm{e}_{\mathrm{ijk}}
$$

em que: $Y_{i j k}=$ fator a ser analisado (variável depen- 
dente); $\mu$ = média geral; $\mathrm{G}_{\mathrm{i}}=$ efeito do $\mathrm{j}$-ésimo genótipo; $\mathrm{S}_{\mathrm{j}}=$ efeito do k-ésimo sistema; $(\mathrm{GS})_{\mathrm{ij}}=$ interação genótipo com o sistema; $\mathrm{e}_{\mathrm{ijk}}=$ erro associado à repetição.

Foi realizada análise da variância pelo programa estatístico STATGRAPHICS (Statistical Graphics System, versão 7,0 - STSC, Inc. and Statistical Graphics Corporation, 1985-91). As médias foram comparadas pelo teste Tukey. A incidência de carnes PSE foi analisada pelo teste do qui-quadrado.

\section{Resultados e Discussão}

Os valores médios, os erros-padrão e os níveis de significância do efeito dos genótipos halotano e dos sistemas de criação sobre o pH e temperatura da carcaça quente encontram-se na Tabela 1.

Os valores médios de $\mathrm{pH}$ inicial nos músculos Longissimus dorsi e Semimembranosus foram significativamente superiores nos suínos halotano homozigotos dominantes em relação aos heterozigotos para o gene halotano. Segundo Ellis (1998), o gene halotano exerce influência na glicólise que ocorre nos músculos logo após a morte e, conseqüentemente, na velocidade e extensão do declínio do pH. Os resultados encontrados estão de acordo com Tam et al. (1998), Sather et al. (1991), Leach et al. (1996), Channon et al. (2000), Fisher et al. (2000), Hamilton et al. (2000) e Culau et al. (2002). Esses resultados indicam que o alelo n possui uma via de ação gênica aditiva para a característica $\mathrm{pH}$.

Os sistemas de criação não influenciaram os valores de $\mathrm{pH}$ inicial do músculo Longissimus dorsi e Semimembranosus. Esses resultados estão de acordo com os obtidos por Warris et al. (1983), Jones et al. (1993), Van der Wal et al. (1993) e Bridi et al. (1998) que, ao compararem o pH inicial da carne de suínos criados em confinamento e ao ar livre não encontraram diferenças significativas.

O genótipo halotano não influenciou os valores de $\mathrm{pH}$ final nos músculos Longissimus dorsi e Semimembranosus. Esses resultados estão de acordo com os encontrados por Culau et al. (2002). Porém, Sather et al. (1991) e Leach et al. (1996) verificaram que o $\mathrm{pH}$ final do lombo de suínos portadores de um alelo halotano foi inferior ao de suínos livres do gene halotano.

O sistema de criação utilizado nas fases de crescimento e terminação dos suínos não afetou os valores médios de $\mathrm{pH}$ final dos músculos Longissimus dorsi e Semimembranosus. Comparando-se os sistemas de criação ao ar livre com o confinado sobre

Tabela 1 - Efeito dos genótipos halotano e dos sistemas de criação no pH inicial e final nos músculos Longissimus dorsi (LD) e Semimembranosus (SM) e na temperatura da carcaça quente (TCQ) - média, erro padrão e nível de significância (Signif.)

Table 1 - The effect of genotype and rearing system on initial and ultimate $\mathrm{pH}$ in Longissimus dorsi and Semimembranosus muscles and on the hot carcass temperature (HCT) - means, standard errors and level of significance (LS)

\begin{tabular}{|c|c|c|c|c|c|c|}
\hline & $\begin{array}{l}\mathrm{N}-\text { animais } \\
\text { Number of pigs }\end{array}$ & $\begin{array}{l}\text { pH inicial LD } \\
\text { Initial pH LD }\end{array}$ & $\begin{array}{c}\text { pH inicial SM } \\
\text { Initial } p H S M\end{array}$ & $\begin{array}{l}\mathrm{pH} \text { final LD } \\
\text { Ultimate } \mathrm{pH} L D\end{array}$ & $\begin{array}{l}\mathrm{pH} \text { final SM } \\
\text { Ultimate } \mathrm{pH} \text { SM }\end{array}$ & $\begin{array}{l}\operatorname{TCQ}\left({ }^{\circ} \mathrm{C}\right) \\
\operatorname{HCT}\left({ }^{\circ} \mathrm{C}\right)\end{array}$ \\
\hline \multicolumn{7}{|l|}{$\begin{array}{l}\text { Genótipo } \\
\text { Genotype }\end{array}$} \\
\hline $\begin{array}{l}\mathrm{Hal}^{\mathrm{NN}} \\
\mathrm{Hal}^{\mathrm{Nn}} \\
\text { Signif. } \\
L S\end{array}$ & $\begin{array}{l}48 \\
48\end{array}$ & $\begin{array}{c}6,3^{\mathrm{a}} \pm 0,06 \\
5,9^{\mathrm{b}} \pm 0,06 \\
0,0004\end{array}$ & $\begin{array}{c}6,5^{\mathrm{a}} \pm 0,06 \\
6,3^{\mathrm{b}} \pm 0,06 \\
0,0041\end{array}$ & $\begin{array}{c}5,5 \pm 0,04 \\
5,5 \pm 0,04 \\
0,7366\end{array}$ & $\begin{array}{c}5,6 \pm 0,02 \\
5,6 \pm 0,02 \\
0,8225\end{array}$ & $\begin{array}{c}32,6 \pm 0,48 \\
32,7 \pm 0,48 \\
0,1052\end{array}$ \\
\hline \multicolumn{7}{|l|}{$\begin{array}{l}\text { Sistema } \\
\text { Rearing system }\end{array}$} \\
\hline $\begin{array}{l}\text { Sem cama } \\
\text { Indoor without bedding }\end{array}$ & 32 & $6,1 \pm 0,07$ & $6,3 \pm 0,07$ & $5,5 \pm 0,05$ & $5,6 \pm 0,03$ & $33,2 \pm 0,43$ \\
\hline $\begin{array}{l}\text { Com cama } \\
\text { Indoor with wood } \\
\text { shavings bedding }\end{array}$ & 32 & $6,2 \pm 0,07$ & $6,5 \pm 0,07$ & $5,5 \pm 0,05$ & $5,7 \pm 0,03$ & $32,7 \pm 0,43$ \\
\hline $\begin{array}{l}\text { Arlivre } \\
\text { Outdoor }\end{array}$ & 32 & $6,0 \pm 0,09$ & $6,3 \pm 0,09$ & $5,5 \pm 0,06$ & $5,6 \pm 0,04$ & $31,9 \pm 0,53$ \\
\hline $\begin{array}{l}\text { Signif. } \\
L S\end{array}$ & 0,1648 & 0,0938 & 0,8800 & 0,1579 & 0,6423 & \\
\hline
\end{tabular}

a,b Médias seguidas de letras diferentes na mesma coluna demonstram diferença significativa $(P<0,01)$.

${ }^{a, b}$ Means with different letter in the same column are significantly different $(P<0,01)$. 
cama de maravalha, Sather et al. (1997) também não constataram diferenças nos valores de $\mathrm{pH}$ final da carne de suínos criados nesses sistemas. Porém, Essén-Gustavsson \& Jensen-Waern (1995), Enfält et al. (1995) e Enfält et at. (1997) encontraram valores de $\mathrm{pH}$ final inferiores na carne de suínos criados ao ar livre em relação aos confinados.

A temperatura da carcaça, medida 45 minutos após o abate, não diferiu entre os genótipos. Resultados semelhantes foram encontrados por Forrest (1998) e Channon et al. (2000).

Entre os sistemas de produção estudados, as médias de temperatura da carcaça medida aos 45 minutos após o abate não diferiram significativamente entre si.

Não houve interação significativa entre o genótipo halotano e sistema de criação para os valores de $\mathrm{pH}$ inicial e final medidos nos músculos Longissimus dorsi e Semimembranosus, bem como para a temperatura da carcaça quente.

A presença do alelo halotano afetou significativamente a perda de líquido por gotejamento na carne suína (Tabela 2). Resultados semelhantes foram encontrados por Sather et al. (1991), EssénGustavsson et al. (1992), Lahucky et al. (1997), Channon et al. (2000), Fisher et al. (2000) e Hamilton et al. (2000). As amostras de carne dos suínos HalNn perderam, em média, 35\% a mais de líquido que as dos HalNN. A carne de suínos com genótipo HalNn foi a que apresentou valores inferiores de $\mathrm{pH}$ inicial. A maior taxa de declínio do pH no músculo dos suínos com genótipo HalNn, associada à temperatura elevada da carcaça, pode ter causado a desnaturação das proteínas miofibrilares, resultando na maior perda da capacidade de retenção de água da carne desses animais. Além disso, na transformação do músculo em carne, nos suínos susceptíveis ao estresse, é ativado, além da glicólise anaeróbica, o ciclo nucleotídeos purínica, para regenerar o ATP. No ciclo nucleotídeos purínica, o AMP é desaminado a IMP e este pode ser degradado a ácido úrico e aumentar a formação de radicais livres. Os radicais livres podem lesionar as membranas celulares e provocar diminuição na capacidade de retenção de água na carne dos suínos susceptíveis ao estresse (Essén-Gustavsson et al., 1988 e Essén-Gustavsson et al., 1992).

A quantidade de líquido perdido durante o descongelamento e a cocção da carne não foi afetada pelo genótipo, concordando com Leach et al. (1996) e Monin et al. (1999). No entanto, Fisher et al. (2000) e Culau et al. (2002) verificaram que, à medida que

Tabela 2 - Efeito dos genótipos halotano e dos sistemas de criação na capacidade de retenção de água da carne suína (média, erro padrão e nível de significância - Signif.)

Table 2 - The effect of genotype and rearing system on the water holding capacity meat - means, standard errors and level of significance (LS)

\begin{tabular}{|c|c|c|c|c|}
\hline & $\begin{array}{l}\text { № animais } \\
\text { Number of pigs }\end{array}$ & $\begin{array}{c}\text { Perda de líquido } \\
\text { por gotejamento (\%) } \\
\text { Drip loss (\%) }\end{array}$ & $\begin{array}{c}\text { Perda de líquido } \\
\text { descongelamento (\%) } \\
\text { Defrost loss (\%) }\end{array}$ & $\begin{array}{c}\text { Perda de líquido } \\
\text { na cocção (\%) } \\
\text { Cooking loss (\%) }\end{array}$ \\
\hline \multicolumn{5}{|l|}{$\begin{array}{l}\text { Genótipo } \\
\text { Genotype }\end{array}$} \\
\hline $\begin{array}{l}\mathrm{Hal}^{\mathrm{NN}} \\
\mathrm{Hal}^{\mathrm{Nn}} \\
\text { Signif. } \\
\text { LS }\end{array}$ & $\begin{array}{l}48 \\
48\end{array}$ & $\begin{array}{c}1,63^{\mathrm{a}} \pm 0,17 \\
2,17^{\mathrm{b}} \pm 0,17 \\
0,0312^{* *}\end{array}$ & $\begin{array}{c}2,54 \pm 0,23 \\
3,06 \pm 0,23 \\
0,1081\end{array}$ & $\begin{array}{c}46,0 \pm 1,62 \\
43,8 \pm 1,62 \\
0,3552\end{array}$ \\
\hline $\begin{array}{l}\text { Sistema } \\
\text { Rearing system }\end{array}$ & & & & \\
\hline $\begin{array}{l}\text { Sem cama } \\
\text { Indoor without bedding }\end{array}$ & 32 & $1,77 \pm 0,21$ & $2,64^{\mathrm{ab}} \pm 0,28$ & $42,2 \pm 1,99$ \\
\hline $\begin{array}{l}\text { Com cama } \\
\text { Indoor with wood } \\
\text { shavings bedding }\end{array}$ & 32 & $1,88 \pm 0,21$ & $2,07^{\mathrm{a}} \pm 0,28$ & $47,9 \pm 1,99$ \\
\hline $\begin{array}{l}\text { Ar livre } \\
\text { Outdoor }\end{array}$ & 32 & $2,05 \pm 0,21$ & $3,62^{\mathrm{b}} \pm 0,35$ & $44,6 \pm 1,99$ \\
\hline $\begin{array}{l}\text { Signif. } \\
L S\end{array}$ & & 0,6601 & $0,0002 *$ & 0,1359 \\
\hline
\end{tabular}

R. Bras. Zootec., v.32, n.6, p.1362-1370, 2003 
aumentou o número de alelos n, a perda de líquido por aquecimento foi maior.

A perda de líquido por gotejamento e durante a cocção da carne não foi afetada pelo sistema de criação. Entretanto, a carne proveniente de suínos criados no sistema ao ar livre perderam mais líquido durante o descongelamento do que a dos criados no confinamento sobre cama de maravalha. A perda de líquido no descongelamento das amostras de carne dos suínos criados no confinamento sobre piso de concreto não diferiu estatisticamente das amostras dos outros dois sistemas citados.

Comparando-se o sistema intensivo de produção ao ar livre com o confinado, Warris et al. (1983), Van der Wal et al. (1993) e Bridi et al. (1998) não encontraram diferenças de perda de líquido por gotejamento da carne de suínos provenientes dos dois sistemas. Porém, Enfält et al. (1995; 1997) verificaram que a carne de suínos criados ao ar livre apresentaram maiores perdas de líquido do que a carne dos animais confinados, como conseqüência dos valores inferiores de pH inicial apresentados por esses animais. Sather et al. (1997) encontraram maior perda de líquido por gotejamento na carne de suínos criados ao ar livre quando comparados aos confinados sobre cama de maravalha, mesmo sem ocorrer diferença entre os sistemas nos valores de $\mathrm{pH}$ final.
Não houve interação significativa entre o genótipo halotano e sistema de criação para as características relacionadas à capacidade de retenção de água na carne suína.

Os valores médios, os erros padrões e os níveis de significância do efeito dos genótipos halotano e dos sistemas de criação sobre a cor, taxa de marmorização encontram-se na Tabela 3.

A média geral do escore atribuído à cor da carne resfriada foi $2,4( \pm 0,059)$, escore inferior ao considerado normal na carne suína que é igua a três, que corresponde a cor rosa cinzento (National Pork Producers Council, 1991).

A presença do alelo halotano não afetou a cor da carne suína. Esses resultados estão de acordo com Sather et al. (1991), que obtiveram similar escore de cor entre os genótipos HalNN e HalNn. No entanto, Lahucky et al. (1997), Channon et al. (2000) e Culau et al. (2002) verificaram que a coloração da carne tornou-se mais pálida com o aumento de alelos n.

A cor da carne suína sofreu influência significativa dos sistemas de produção estudados. Suínos criados ao ar livre apresentaram a carne mais escura do que aqueles criados em confinamento sobre cama de maravalha. A cor da carne dos suínos criados no confinamento sobre piso de concreto não diferiu dos outros dois sistemas de criação. Warris et al. (1983)

Tabela 3 - Efeito dos genótipos halotano e dos sistemas de criação na qualidade da carne (média, erro padrão e nível de significância - Signif.)

Table 3 - The effect of genotype and rearing system on the meat quality - means, standard errors and level of significance (LS)

\begin{tabular}{|c|c|c|c|c|}
\hline & $\begin{array}{c}\text { No- animais } \\
\text { Number of pigs }\end{array}$ & $\begin{array}{l}\text { Cor } \\
\text { Color }\end{array}$ & $\begin{array}{c}\text { Marmorização } \\
\text { Marbling }\end{array}$ & $\begin{array}{c}\text { Maciez }\left(\mathrm{Kg} / \mathrm{cm}^{2}\right) \\
\text { Tenderness }\left(\mathrm{Kg} / \mathrm{cm}^{2}\right)\end{array}$ \\
\hline \multicolumn{5}{|c|}{$\begin{array}{l}\text { Genótipo } \\
\text { Genotype }\end{array}$} \\
\hline $\begin{array}{l}\mathrm{Hal}^{\mathrm{NN}} \\
\mathrm{Hal}^{\mathrm{Nn}} \\
\text { Signif. } \\
\text { LS }\end{array}$ & $\begin{array}{l}48 \\
48\end{array}$ & $\begin{array}{c}2,4 \pm 0,08 \\
2,3 \pm 0,08 \\
0,7907\end{array}$ & $\begin{array}{c}1,8 \pm 0,083 \\
1,6 \pm 0,083 \\
0,1361\end{array}$ & $\begin{array}{c}4,5 \pm 0,15 \\
4,7 \pm 0,15 \\
0,2618\end{array}$ \\
\hline
\end{tabular}

Sistema

Rearing system

Sem cama

Indoor without bedding

Com cama

Indoor with wood

shavings bedding

Ar livre

32

$2,4^{\mathrm{ab}} \pm 0,10$

$1,7 \pm 0,09$

$4,5 \pm 0,18$

Outdoor

32

$2,2^{\mathrm{b}} \pm 0,10$

$1,8 \pm 0,09$

$4,3 \pm 0,18$

Signif.

32

$2,5^{\mathrm{a}} \pm 0,12$

$1,5 \pm 0,009$

$5,0 \pm 0,18$

LS

a,b Médias seguidas de letras diferentes na mesma coluna demonstram diferença significativa $(P<0,1)$.

$a, b$ Means with different letter in the same column are significantly different $(P<0,1)$. 
e Bridi et al. (1998) verificaram que suínos criados ao ar livre apresentaram carne de coloração mais escura que os confinados. Como os suínos criados ao ar livre exercitam-se mais que os do confinamento, pode ocorrer maior concentração de mioglobina no músculo, causando uma coloração mais escura na carne desses animais. Entretanto, Van der Wal et al. (1993) e Jones et al. (1993) não encontraram diferença na cor da carne de suínos criados nos dois sistemas.

A presença do alelo halotano não afetou a maciez da carne. Resultados semelhantes foram verificados por Leach et al. (1996) e Channon et al. (2000). Todavia, Fisher et al. (2000) constataram que a carne proveniente de suínos do genótipo HalNn apresentou força de cisalhamento maior, ou seja, carne mais dura. Os autores atribuíram este resultado ao fato de a carne desses animais perder mais água durante o cozimento.

A força de cisalhamento da carne de suínos submetidos aos diferentes sistemas de criação foi estatisticamente semelhante. Resultados semelhantes foram encontrados por Bridi et al. (1998). No entanto, Van der Wal et al. (1993), Enfält et al. (1997) e Sather et al. (1997) verificaram que a força de cisalhamento foi maior na carne de suínos criados ao ar livre. Van der Wal et al. (1993) consideraram as diferenças encontradas irrelevantes porque a análise do painel de degustação não acusou diferença entre os sistemas para esta característica.

A carne dos suínos com genótipo HalNN e HalNn não apresentou diferença estatística para os valores de escore subjetivo de taxa de marmorização. Entretanto, Kukoyi et al. (1981), Leach et al. (1996) e Tam et al. (1998) verificaram que os suínos do genótipo halotano heterozigoto apresentaram menor taxa de marmorização no lombo que os homozigotos dominante.

Não houve diferença significativa na taxa de marmorização da carne dos suínos criados nos sistemas de produção estudados. Esses resultados estão de acordo com Van der Wal (1991) e Bridi et al. (1998). Não foi verificado efeito da interação genótipo e sistema de criação sobre a taxa de marmoreio encontrada na carne suína.

Não houve interação entre o genótipo halotano e os sistemas de produção sobre a cor, maciez e taxa de marmorização da carne suína.

A freqüência de carcaças com carne PSE nos genótipos halotano podem ser visualizados na Figura 1.
A análise do Qui-quadrado mostrou relação $(\mathrm{P}<0,01)$ do genótipo halotano com a freqüência de carcaças com carnes PSE. Os suínos portadores de uma cópia do gene halotano (HalNn) apresentaram uma freqüência mais elevada de carcaças com carnes PSE que aqueles livres do gene halotano (HalNN). Leach et al. (1996) encontraram maior freqüência de PSE em carcaças provenientes de suínos com genótipo halotano heterozigoto em relação aos homozigotos dominantes. Culau et al. (2002) evidenciaram relação do gene halotano com a incidência de carcaças PSE. Classificando as carcaças através dos valores de $\mathrm{pH}$ inicial, os autores encontraramdo 58,82\% de carcaças com carne PSE em suínos heterozigotos contra 36,56\% de carcaças provenientes de suínos homozigotos dominantes. Channon et al. (2000) e Fisher et al. (2000) verificaram que a presença de um alelo halotano aumentou a freqüência de carcaças com carne PSE em cinco e quatro vezes, respectivamente.

No presente trabalho, do total das carcaças que apresentaram PSE, 75\% eram de suínos portadores de uma cópia do gene halotano e os outros 25\% eram carcaças de suínos livres do gene halotano. Esses resultados estão de acordo com Leach et al. (1996), Channon et al. (2000), Fisher et al. (2000) e Culau et al. (2002) que evidenciaram que a presença do gene halotano teve expressiva contribuição na incidência de carnes PSE, embora, nem toda a carne PSE tenha sido causada pelo gene halotano, evidenciando que o manejo pré abate, também, teve participação na incidência de carnes PSE.

A análise do Qui-quadrado demonstrou não haver relação entre sistema de criação e freqüência de carcaças com carne PSE $(\mathrm{P}>0,05)$, conforme pode

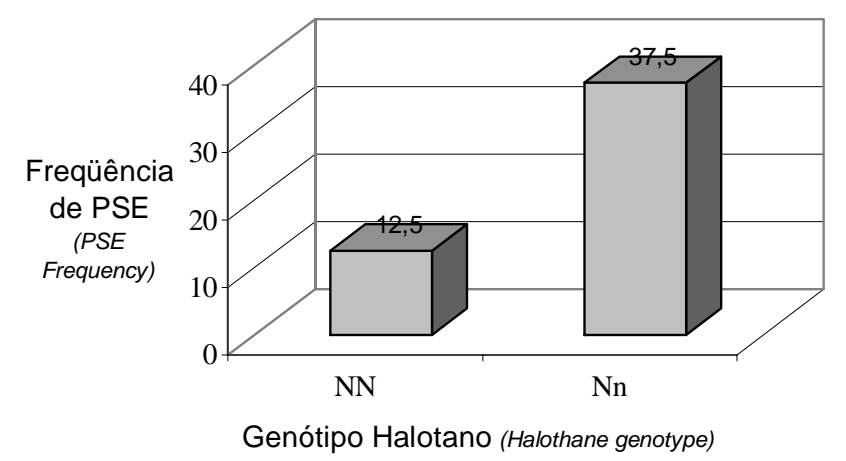

Figura 1 - Freqüência de carcaças PSE em relação ao genótipo halotano.

Figure 1 - PSE frequency as the halothane genotype. 
ser visualizado na Figura 2. O sistema de criação confinado sobre piso de concreto apresentou 34,4\% de carcaças com carnes PSE, o sistema confinado sobre cama de maravalha 15,6 e o sistema de criação ao ar livre 25\% de carcaças com carne PSE. Esses resultados estão de acordo com Jones et al. (1993) e Enfält et al. (1997) que também não encontraram efeito significativo do ambiente de criação na incidência de carnes PSE. Entretanto, Barton-Gade \& Blaabjerg (1989) constataram que suínos criados ao ar livre apresentaram maior concentração de glicose e maior produção de lactato nos músculos após o abate, provocando aumento da incidência de carcaças com carne PSE. Resultados semelhantes foram verificados por Sather et al. (1997) que constataram que no inverno suínos criados ao ar livre no inverno apresentaram maior incidência de carcaças PSE, quando comparados com os criados em confinamento sobre cama de maravalha.

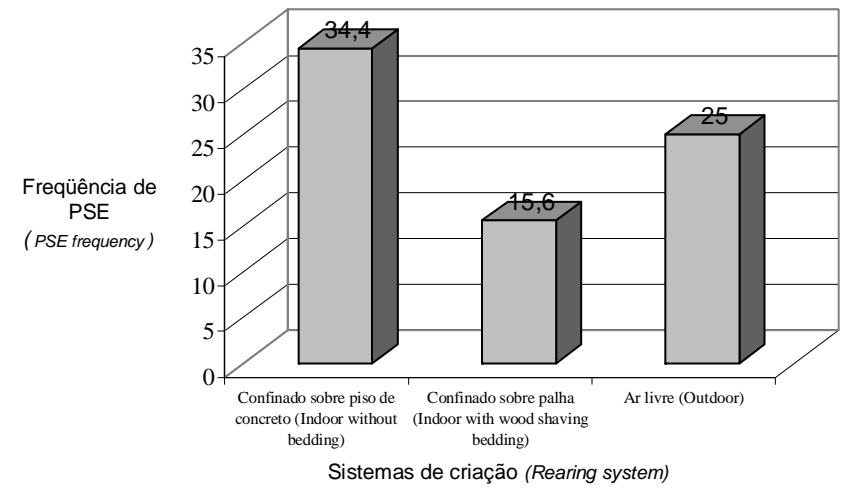

Figura 2 - Freqüência de carcaças PSE em relação ao sistema de criação.

Figure 2 - PSE frequency as the rearing system.

Durante o experimento, foi identificada apenas uma carcaça com carne DFD, carne que se caracteriza por ter a superfície de corte muito escura, seca e firme, como conseqüência de $\mathrm{pH}$ final do músculo Longissimus dorsi maior que seis. A carcaça era proveniente de um suíno com genótipo halotano heterozigoto criado no sistema intensivo ao ar livre.

\section{Conclusões}

A qualidade da carne foi afetada pela presença do alelo recessivo do gene halotano. Músculos de suínos com genótipo halotano heterozigoto apresentaram valores inferiores de $\mathrm{pH}$, menor capacidade de retenção de água e uma freqüência três vezes maior de carcaças apresentando a condição PSE.

Os sistemas de criação estudados não afetaram a qualidade da carne suína em relação ao pH, capacidade de retenção de água e incidência de PSE.

Não houve efeito significativo da interação genótipo halotano e sistema de criação para nenhuma das características de qualidade da carne suína.

\section{Literatura Citada}

BARTON-GADE, P.; BLAABJERG, L.O. Preliminary observations on the behaviour and meat quality of free range pigs. In: INTERNATIONAL CONGRESS OF MEAT SCIENCE AND TECHNOLOGY, 35., 1989, Denmark. Proceedings... Denmark, 1989. p.1002-1005.

BRIDI, A.M.; MÜLLER, L.; RIBEIRO, J.A.R. Indoor vs. outdoor-rearing of pigs, performance, carcass and meat quality. In: INTERNACIONAL CONGRESS OF MEAT SCIENCE AND TECHNOLOGY, 44., 1998, Baercelona. Proceedings... Barcelona, 1998. p.114-117.

CHANNON, H.A.; PAYNE, A.M.; WARNER, R.D. Halothane genotype, pre-slaughter handling and stunning method all influence pork quality. Meat Science, v.56, p.291-299, 2000.

CULAU, P.O.V; LÓPEZ, J.; RUBENSAM, J. M. et al. Influência do gene halotano sobre a qualidade da carne suína. Revista Brasileira de Zootecnia, v.131, n. 2, p. 954-951, 2002.

EIKELENBOOM, G.; CAMPION, D.R.; KAUFFMAN, R.G. et al. Early post mortem methods of detecting ultimate porcine muscle quality. Journal of Animal Science, v.39, n.2, p.303-08, 1974.

ELLIS, M.; WEBB, A.J.; AVERY, P.J. et al. The influence of terminal sire genotype, sex, slaughter weight, feeding regime and slaughter-house on growth performance and carcass and meat quality in pigs and on the organoleptic properties of fresh pork. Animal Science, v.62, p.521-530, 1996.

ELLIS, M. Genetic and nutricional influence on pork quality. In: SIMPÓSIO SOBRE RENDIMENTO E QUALIDADE DA CARNE SUÍNA, 1., 1998, Concórdia. Anais... Concórdia: EMBRAPA, 1998. p.25-54.

ENFÄLT, A.; LUNDSTRÖM, K.; HANSSON, I. et al. The Effects of outdoor-rearing on carcass composition, technological and sensory meat quality in cross-bred pigs with yorkshire or duroc as terminal sire. In: INTERNACIONAL CONGRESS OF MEAT SCIENCE AND TECHNOLOGY PROCCEDINGS, 41, 1995, Texas. Proceedings... Texas: American Meat Science Association, 1995, v.2, p.102-103.

ENFÄLT, A.; LUNDSTRÖM. K.; HANSSON, I. et al. Effects of outdoor rearing and sire breed (Duroc or Yorkshire) on carcass composition and sensory and technological meat quality. Meat Science, v.45, n.1, p.1-15, 1997.

ESSÉN-GUSTAVSSON, B.; KARLSTRÖM, K.; 
LUNDSTRÖM, K. Muscle metabolism and glycogen depletion within fibre types at slaughter in pigs with different halothane genotypes. Relation to meat quality properties. In: INTERNATIONAL CONGRESS OF MEAT SCIENCE AND TECHNOLOGY, 34., 1988, Austrália. Proceedings... Austrália, 1988. p.34-38.

ESSÉN-GUSTAVSSON, B.; KARLSTRÖM, K.; LUNDSTRÖM, K. Muscle fibre characteristics and metabolic response at slaughter in pigs of different halothane genotypes and their relation to meat quality. Meat Science, v.31, p.111, 1992.

ESSÉN-GUSTAVSSON, B.; JENSEN-WAERN, M. Muscle characteristics and metabolic response at slaughter in domestic pigs reared indoors or outdoors. In: INTERNATIONAL CONGRESS OF MEAT SCIENCE AND TECHNOLOGY, 39., 1993, Canadá. Proceedings... Canadá, 1993.

FISHER, P.; MELLETT, F.D.; HOFFMAN, L.C. Halothane genotype and pork quality. 1. Carcass and meat quality characteristics of three halothane genotypes. Meat Science, v.54, p.97-105, 2000.

FORREST, J.C. Measuring pork quality. In: RECIPROCAL MEAT CONFERENCE, 1998, Connecticut. Proceedings... Connecticut: American Meat Science Association, 1998.

FUJII, J.; OTSU, K.; ZORZATO, F. et al. Identification of a mutation in porcine ryanodine receptor associated with malignant hyperthermia. Science, v.253, n.2, p.448-451, 1991.

GIBON, A.; SIBBALD, A.R.; THOMAS, C. Improved sustainability in livestock systems, a challenge for animal production science. Livestock Production Science, v.61, p.107-110, 1999.

HAMILTON, D.N.; ELLIS, M.; MILLER, K.D. et al. The effect of the halothane and rendement napole genes on carcass and meat quality characteristics of pigs. Journal of Animal Science, v.78, p.2862-2867, 2000.

JONES, S.D.M.; SCHAEFER. A.L.; DYCK, R. et al. The effects of fattening pigs in indoor pens on live performance, carcass composition and meat quality. In: INTERNACIONAL CONGRESS OF MEAT SCIENCE AND TECHNOLOGY, 39., 1993, Canadá. Proceedings... Canadá, 1993.

KLONT, R.E.; LAMBOOY, E. Influence of preslaughter muscle temperature on muscle metabolism and meat quality in anesthetized pigs of different halothane genotypes. Journal of Animal Science, v.73, p.96-107, 1995.

KUKOYI, E.A.; ADDIS, P.B.; McGRATH, C.J. et al. Porcine stress syndrome and postmortem muscle characteristics of two purebreds and three specific terminal crosses. Journal of Animal Science, v.52, n.2, p.278-284, 1981.

LAHUCKY, R.; CHRISTIAN, L.L.; KOVAC, L. et al. Meat quality assessed ante-and post mortem by different ryanodine receptor gene status of pigs. Meat Science, v.47, n.3/4, p.277-285, 1997.

LEACH, L.M.; ELLIS, M.; SUTTON, D.S. et al. The growth performance, carcass characteristics, and meat quality of halothane carrier and negative pigs. Journal of Animal Science, v.74, p.934-943, 1996.

MILLER, S.A.; DYKES, D.D.; POLESKY, H.F. A simple salting out procedure for extracting DNA from human necleated cells. Nucleic Acids Research, v.16, n.4, p.1215, 1988.
MONIN, G.; LARZUL, C.; LE ROY, P. et al. Effects of the halothane genotype and slaughter weight on textura of pork. Journal of Animal Science, v.77, p.408-415, 1999.

NATIONAL PORK PRODUCERS COUNCIL. Procedures to Evaluate Market Hogs. 3.ed. Des Moines, Iowa, 1991.

OLIVER, A.M.; GISPERT, M.; DIESTRE, A. The effects of breed and halothane sensitivity on pig meat quality. Meat Science, v.35, p.105-118, 1993.

OURIQUE, J.M.R. Características físico-químicas e organolépticas e suas relações na avaliação da qualidade da carne suína. Porto Alegre: Universidade Federal do Rio Drande do Sul, 1989. 104p. Dissertação (Mestrado em Zootecnia) - Universidade Federal do Rio Drande do Sul, 1989.

OURIQUE, J.M.R.; NICOLAIEWSKY, S. Características físicoquímicas e organolépticas e suas relações na avaliação da qualidade da carne suína. Revista Brasileira de Zootecnia, v.19, n.2, p.118-125, 1990.

SAMBROOK, J.; FRITSCH, E.F.; MANIATIS, T. Molecular cloning: a laboratory manual. 2.ed. New York: Cold Spring Harbor Laboratory, 1989. v. 3.

SATHER, A.P.; MURRAY, A.C.; ZAWADSKI, S.M. et al. The effect of the halothane genotype on pork production and meat quality of pigs reared under commercial conditions. Canadian Journal of Animal Science, v.71, p.959-967, 1991.

SATHER, A.P.; JONES, S.D.M.; SCHAEFER, A.L. et al. Feedlot performance, carcass composition and meat quality of free-range reared pigs. Canadian Journal of Animal Science, v.77, p.225-232, 1997.

TAM, L.G.; BERG, E.P.; GERRARD, D.E. et al. Effect of halothane genotype on porcine meat quality and myoglobin autoxidation. Meat Science, v.49, n.1, p.41-53, 1998.

Van der WAL, P.G.; MATEMAN, G.; VRIES, A.W. et al. 'Scharrel' (free range) pigs: carcass composition, meat quality and taste-panel studies. Meat Science, v.34, p.27-37, 1993.

WARRIS, S.C.K.; KESTIN, S.C.; ROBINSON, J.M. A note on the influence of rearing environment on meat quality in pigs. Meat Science, v.9, p.271-279, 1983.

WARRISS, P.D.; BROWN, S.N. The relationships between initial $\mathrm{pH}$, reflectance and exudation in pig muscle. Meat Science,v.20, p.65-74, 1987.

WARRISS, P.D.; BROWN, S.N. Bem-estar de suínos e qualidade da carne: uma visão Britânica. In: CONFERÊNCIA VIRTUAL INTERNACIONAL SOBRE QUALIDADE DE CARNE SUÍNA, 1., 2000, Concórdia. Anais... Concórdia: EMBRPA, 2000, 4 p.Disponível on line em http:www. Cnpsa. embrapa. br/pork/ palestra.html.

WHIPPLE, G.; KOOHMARAIE, M.; DIKEMAN, M.E. et al. Evaluation of attributes that affect longissimus muscle tenderness in Bos taurus and Bos indicus cattle. Journal Animal Science, v.68, p.2716-2728, 1990. 